\title{
Sleep as an Occupation in College Students
}

\section{DOMINICAN UNIVERSITY of CALIFORNIA}

Capstone Advisor: Ruth Ramsey, Ed.D., OTR/L

Dominican University of California, Department of Occupational Therapy Fall 2015

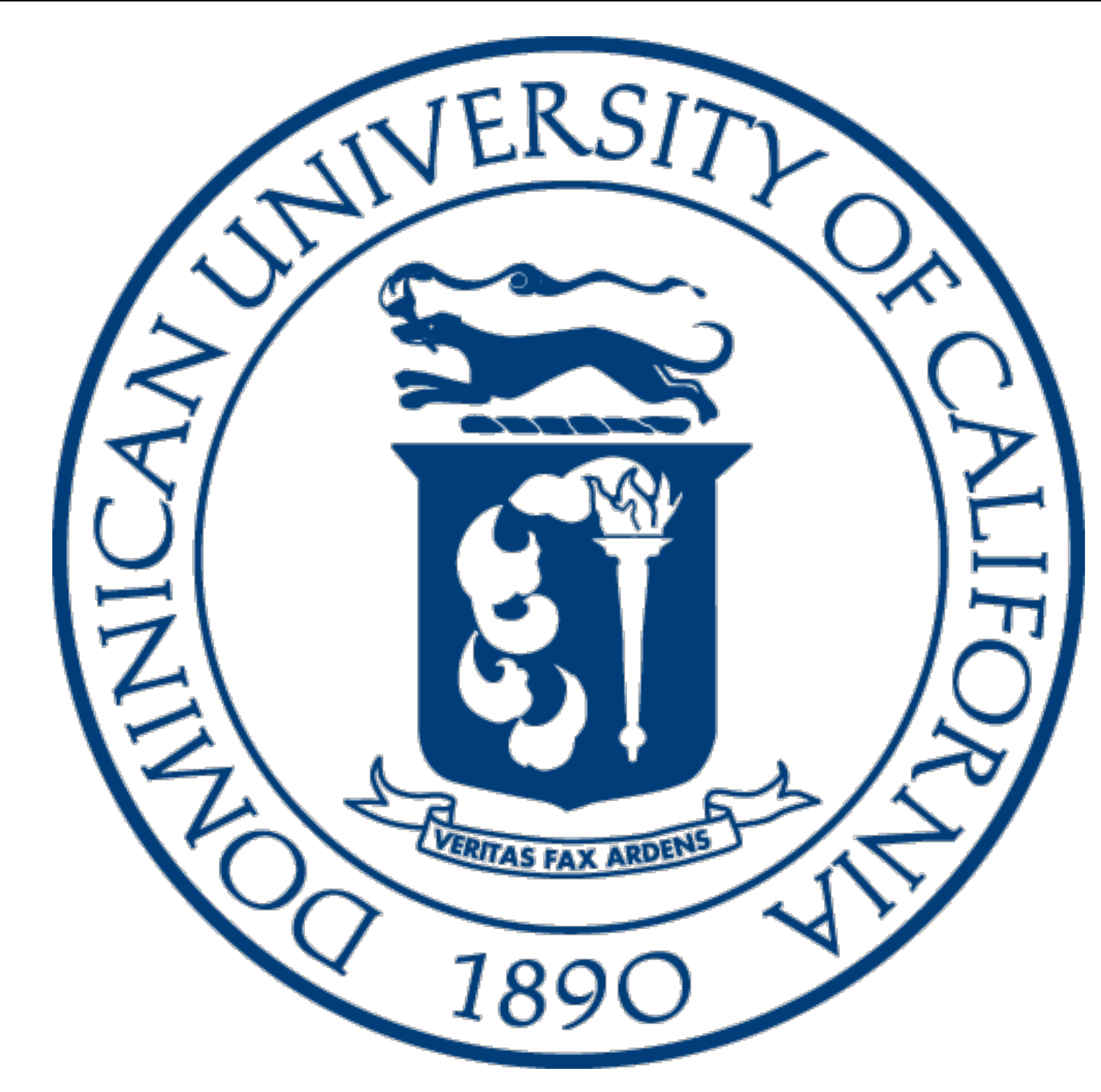

\section{INTRODUCTION}

The average person spends $1 / 3$ of his or her life sleeping (Curico et al., 2006)

College students have poor quality and quantity of sleep resulting in $\downarrow$ performance in student related occupations, and academic performance.

Minimal evidence examines the relationship between self-efficacy, Minimal evidence examines the relationship between seff
sleep, and occupational performance in college students. - Sleep, and occupational performance in college students. modifying the environment and performance patterns of college students.

STATEMENT OF
PURPOSE
1. Measure sleep quality and patterns of sleep in undergraduate
college students
2. Explore the relationship between sleep, academic self-efficacy
and student characteristics
- First-generation college students
- Students with disabilities
Student athletes

Review of Literature

SLEEP AS AN OCCUPATION

- Sleep is vital for all human life.

$\downarrow$ sleep quality may result in behavioral, occupational, psychological, cogntive impairments and even premature death (Curico, et al., 2006).

SLEEP DISORDERS

- Common sleep disorders include insomnia, sleep apnea and narcolepsy (Buck, 2013).

- Narcolepsy affects $16 \%$ of college students (Gaultney, 2010). COLLEGE STUDENTS

University students often have trouble falling asleep and staying asleep Athletes, first generation students \& students with disabilities were shown to have a higher risk of experiencing sleep disturbances.

SLEEP AND OCCUPATIONAL THERAPY

Rest and sleep are categorized as occupations in the Occupational Therapy Practice Framework (AOTA, 2014).

Sleep is the only occupation that cannot be performed by another person (Pedretti, 2010).

. sleep disorders (Leland et al., 2014).

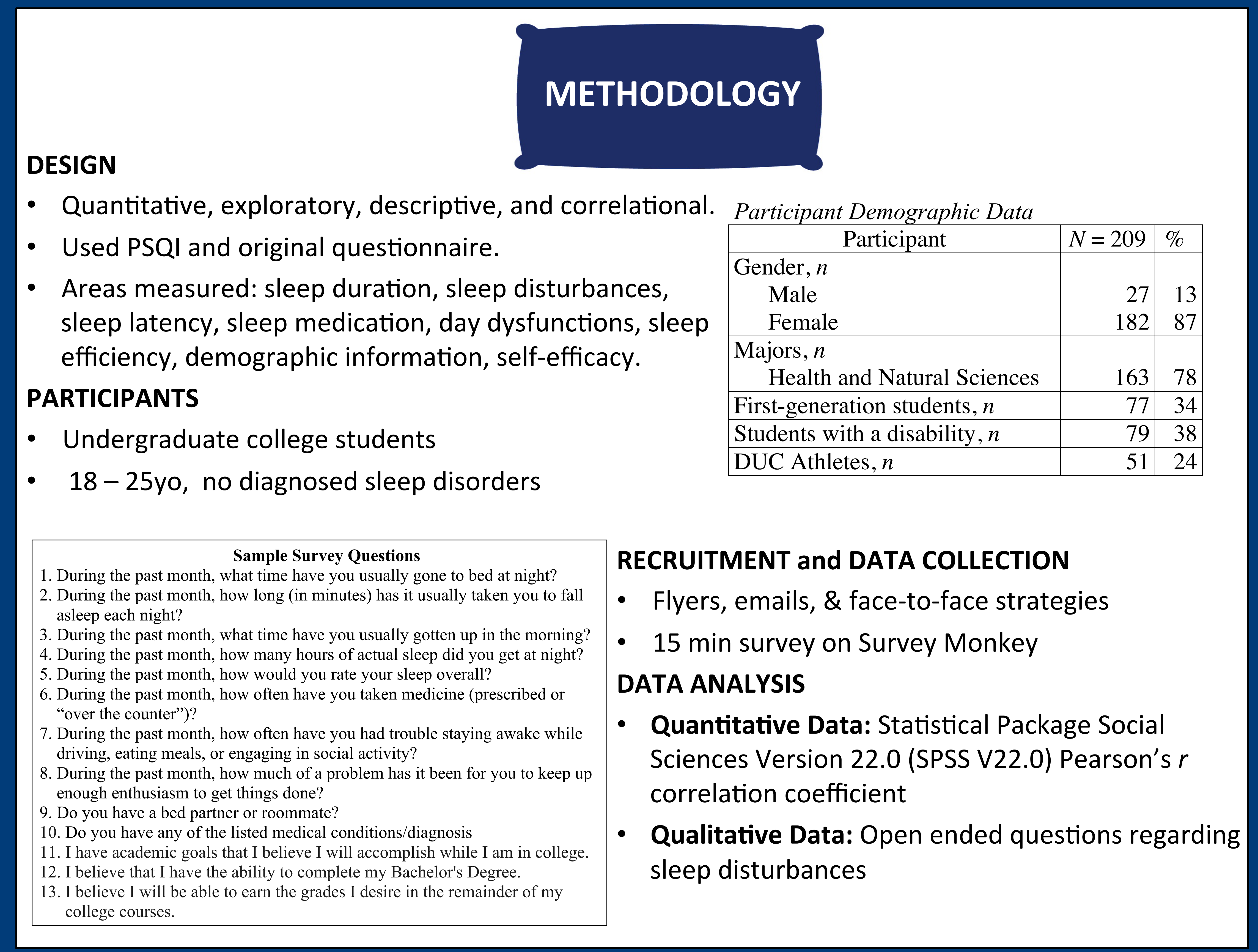

RESULTS

QUANTITATIVE DATA

Sleep Quality of College Students

PSQI scores: 135 (64.6\%) participants

reported poor sleep quality and 74 (35.4\%)

participants reported good sleep quality.

Weak positive correlation $(r=.33)$

between PSQI scores and disability; sleep duration and GPA.

Average number of sleep hours reported

by participants is 6.68 hours.

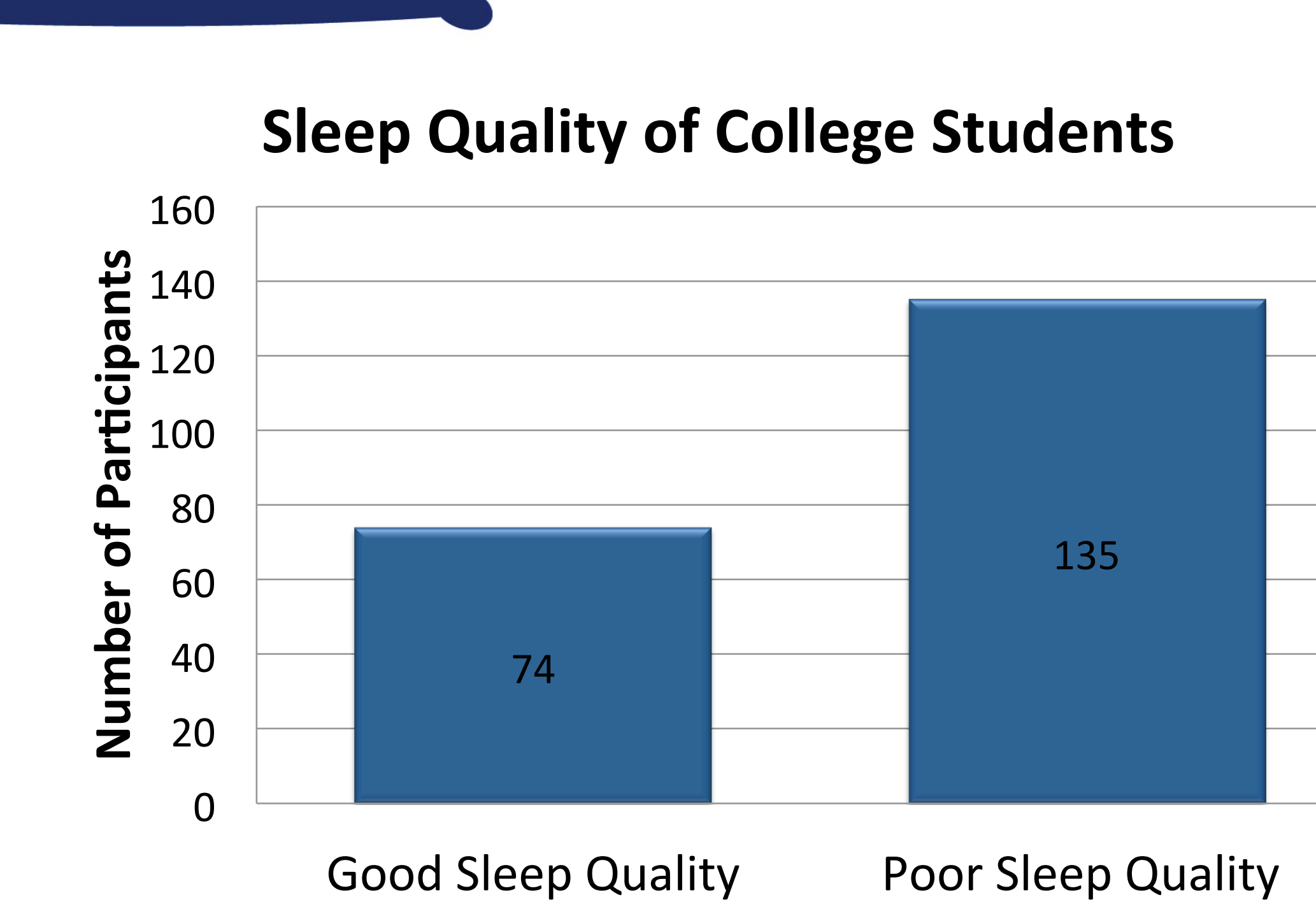

4. No significant correlations between PSQI scores, participant demographics or self-efficacy responses.

QUALITATIVE DATA

1. Environmental factors such as lighting, temperature, and noise affect quality of sleep.

2. Sleep behaviors: sleep talking, snoring, tossing and turning, and coughing.

3. Impact of partners and roommates: noise, movement, and snoring.

\section{DISCUSSION}

AND

IMPLICATIONS

DISCUSSION

- Results support existing evidence suggesting college students are sleep deprived.

Over $1 / 2$ of participants reported sleep issues that could be addressed by an occupational therapist.

SUGGESTIONS FOR FUTURE RESEARCH

- Focus on key finding, which suggests that over $1 / 2$ of undergraduate students have poor sleep quality and/or quantity.

- Conduct further studies with college students to determine specifically what is affecting their sleep quality and quantity and how it varies across time.

Focus on specific student categories, ex: students with disabilities SUGGESTIONS FOR OCCUPATIONAL THERAPY

- OTs can help improve the performance of sleep as an occupation.

- Interventions to improve sleep quality through environmental modifications, client education, and promotion of good sleeping habits.

Create sleep promotion programs targeting young adults to address their unique biological and physical needs.

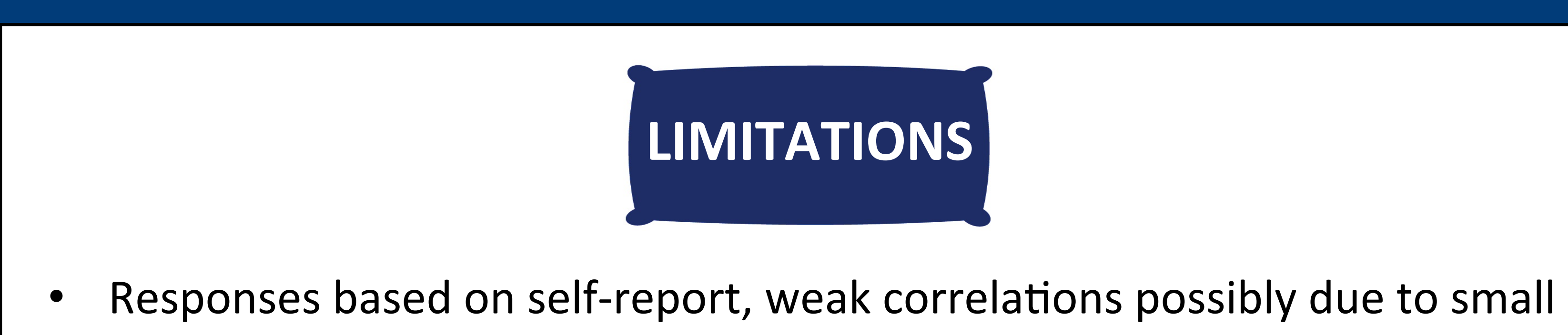
sub-category sample sizes.

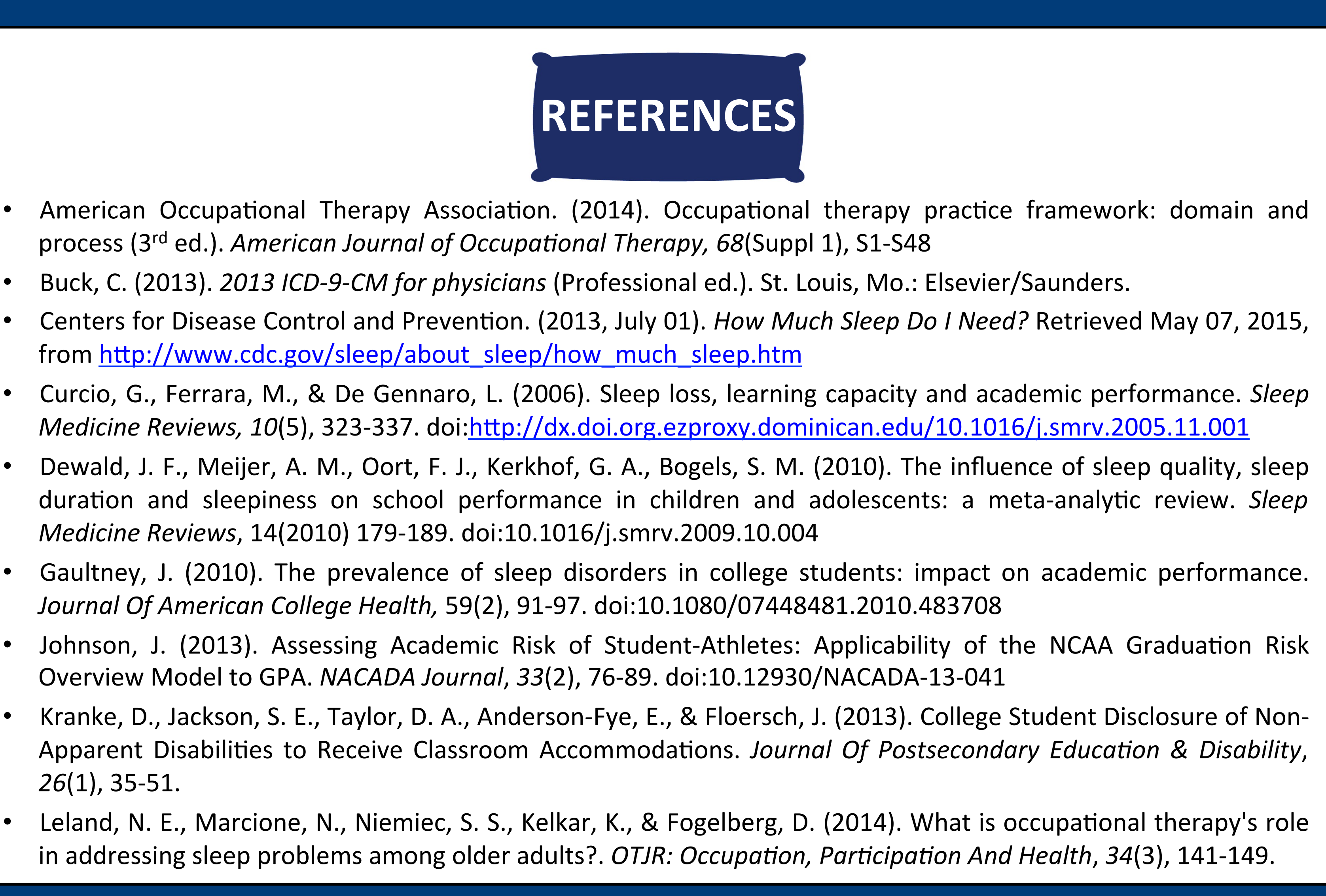

